Yearbook of Population Research in Finland 30 (1992), pp 44-67

\title{
Time Series Analysis of Three Centuries of the Childbearing and Fertility Process in Finland
}

\author{
M. NABIL EL-KHORAZATY \\ Professor \\ Department of Statistics \\ Cairo University
}

\section{Introduction}

Finland is one of a very few countries which have reliable population and vital statistics data from as early as the mid-eighteenth century. While Finland enjoys this wealth of demographic records that has inspired many researchers to conduct a large number of historical studies on fertility behavior, there are still some remaining aspects of childbearing and fertility processes that were not recorded and may be tackled now with the availability of new demographic and statistical models and techniques.

Observed indices of childbearing and the family life cycle, such as maternal ages at the birth of the first and last child and the length of reproductive life spans, require detailed biographical information on the dates on which these events occurred. In addition, direct determinants of the fertility level and pattern in terms of nuptiality, contraception and lactation are usually obtained from fertility survey data. But such historical and detailed information were not recorded even for a country like Finland. Knowledge of childbearing/family life cycle events and their determinants will enrich our understanding of and help to elucidate the mechanisms and reasons behind demographic changes in Finland since the early eighteenth century.

Using only sets of age-specific fertility rates (ASFRs), Horne, El-Khorazaty and Suchindran (1990) introduced a childbearing model, which provides, among other things, synthetic estimates of the mean maternal ages at the birth of the first and last child and the length of the reproductive life span. Quantum measures of period fertility, ASFRs, are used to compute the childbearing temporal indices. The model was applied to cross-sectional data for 16 Arab and 36 World Fertility Survey countries (Horne and El-Khorazaty, 1987; Horne, El-Khorazaty and Suchindran, 1990, respectively) and to historical time series data for 58 developing and developed countries during the twentieth century (El-Khorazaty and Horne, 1992).

Bongaarts (1978) proposed a model which postulates that the four main factors accounting for fertility variations among populations are differences in nuptiality, contraception, postpartum infecundability (due to lactation) and abortion, all known as intermediate fertility variables (IFVs). The relationships among these factors and their effect on fertility are characterized by four fertility-inhibiting indices. However, fertility survey data are necessary for calculating the indices. 
Noting that both the childbearing and the fertility-inhibiting indices are manifestations of the prevailing fertility level and behavior in a society, El-Khorazaty (1991) discovered that the correspondence between the two sets of indices is so strong that the easy-to-calculate childbearing indices can be used to estimate the moredifficult-to-obtain fertility-inhibiting indices via a regression model, with a very high degree of accuracy. The main advantage of El-Khorazaty's regression model is that a time series for each fertility-inhibiting index can be calculated based only on sets of ASFRs. Without the regression model the set of fertility-inhibiting indices can be computed only directly, using Bongaarts model, when sample survey data are available, and then not on an annual basis.

Consequently, with only knowledge of ASFRs required to calculate the childbearing temporal indices (through the childbearing model), fertility-inhibiting indices of Bongaarts' model can be estimated (through the regression model). The main purpose of this paper is to use this interlink among the three models in order to achieve a more comprehensive macro-level picture about the fertility and childbearing process in Finland, and extend the wealth of available information by estimating the two sets of historical time series data on childbearing and fertility-inhibiting processes for the period (1722-2022). First, the two sets of indices will be calculated for the period (1776 - 1987) for which ASFRs are available. Second, applying the Box-Jenkins (1976) time series techniques, future and reverse forecasts of the two sets of indices will be computed.

\section{Methodology and data}

The three centuries (1722-2022) of demographic development of Finland may be divided, according to data availability, into three subperiods. The first spans 1722 to 1775 , for which only data on four crude demographic variables, namely, crude birth rate (CBR), crude death rate (CDR), natural increase rate (NIR) and crude marriage rate (CMR), are accessible. The second period covers the years from 1776 to 1987, in which ASFRs are available, in addition to the infant mortality rate (IMR) and the other four crude demographic variables. For the third period (1988-2022), projections of crude demographic variables CBR, CDR and NIR have been calculated by the United Nations (1989).

Age-specific fertility rates (ASFRs), available for the period 1776-1987, were used to obtain childbearing temporal indices. The childbearing model is derived in detail in Horne, El-Khorazaty, and Suchindran (1990), and thus will not be repeated here except to define the indices. Briefly, let $\mathrm{f}(\mathrm{x}) \mathrm{dx}$ denote the probability that a woman of age $\mathrm{x}$ will have a birth in the age interval $(\mathrm{x}, \mathrm{x}+\mathrm{dx})$. Treating the birth process as a renewal process $(\operatorname{Cox}, 1962)$, then $g_{1}(x) d x\left(=f(x) \cdot \exp \left[-\int_{a}^{x} f(t) d t\right] d x\right)$ is the probability that the birth will be the woman's first birth, and $g_{L}(x) d x(=f(x)$. $\left.\exp \left[-\int_{x}^{\beta} f(t) d t\right] d x\right)$ is the probability that the birth will be her last birth. Then the projected mean maternal ages at first (PAFB) and last (PALB) birth are given by

$$
\mathrm{PAFB}=\left[\int_{a}^{\beta} \mathrm{x} \cdot \mathrm{g}_{1}(\mathrm{x}) \mathrm{dx}\right] \div \mathrm{S}_{1} \quad \text { for } \alpha<\mathrm{x}<\beta
$$

and

$$
\mathrm{PALB}=\left[\int_{\alpha}^{\beta} \mathrm{x} \cdot \mathrm{g}_{\mathrm{L}}(\mathrm{x}) \mathrm{dx}\right] \div \mathrm{S}_{\mathrm{L}} \quad \text { for } \alpha<\mathrm{x}<\beta,
$$

where $S_{1}=S_{L}=\int_{\alpha}^{\beta} g_{1}(x) d x \leq 1$ is the probability that a newborn girl will ever become a mother, and $\alpha$ and $\beta$ represent the lower and upper ages of childbearing, respect- 
ively. Numerical integration of formulas (1) and (2) can be obtained to carry out the calculations using the discrete seven five-year age-specific fertility rates as

$$
\mathrm{PAFB}=\left[15-50 \cdot \exp (-\mathrm{TFR})+\sum_{15}^{50} \exp \left(-\operatorname{TFR}\left(\mathrm{x}_{\mathrm{i}_{+}}\right)\right)\right] \div \mathrm{S}_{1}
$$

and

$$
\text { PALB }=\left[50-15 \cdot \exp (-T F R)-\exp (-T F R) \cdot \sum_{15}^{50} \exp \left(T F R\left(x_{i+}\right)\right)\right] \div \mathrm{S}_{1}
$$

where TFR is the period total fertility rate, TFR(x) is the cumulative fertility rate up to age $x, x_{i+}$ is the midpoint of the age interval $(x, x+5)$, and $S_{1}=1-\exp (-T F R)$. Then $\exp \left[-\operatorname{TFR}\left(\mathrm{x}_{\mathrm{i}+}\right)\right]$ is computed as the average of $\exp [-\operatorname{TFR}(\mathrm{x})]$ and $\exp [-\operatorname{TFR}(\mathrm{x}+5)]$. Expressions for the variances of PAFB and PALB are given in Horne, El-Khorazaty, and Suchindran (1990).

The unconditional projected mean reproductive life span (PRLS) may be computed as the simple difference between the PAFB and the PALB. The PRLS conditional upon a woman having at least two births is given by

$$
\mathrm{PRLS}=\left(\mathrm{S}_{1} \div \mathrm{B}_{2}\right) \text {. }(\mathrm{PALB}-\mathrm{PAFB})
$$

where $\mathrm{B}_{2}$ is the probability that a woman will have at least two births and is expressed as $\left[\int_{\alpha}^{\beta} \mathrm{f}(\mathrm{x}) . \int_{\alpha}^{\mathrm{x}} \mathrm{f}(\mathrm{t}) \mathrm{dt} \cdot \exp \left[-\int_{a}^{\mathrm{x}} \mathrm{f}(\mathrm{t}) \mathrm{dt}\right] \mathrm{dx}\right]$, which simplifies to [1-exp(-TFR)TFR.exp(-TFR)].

The interpretations of these synthetic indices are similar to that of the TFR, of which they are functions. For example, the PALB is the mean age at the birth of the last child that will be experienced by a new cohort of women if they reproduce according to the given set of ASFRs.

The available ASFRs were substituted into formulas (3)-(5) to obtain estimates of the PAFB, the PALB, and the PRLS, and their standard errors for the second period (1776-1987). The data for our analysis are taken mainly from Lutz (1987b). Time series data on ASFRs for the period 1776-1983 are given in Appendix C in his book, in which data for the earlier period is based on the work of Turpeinen (1979). For recent years, Turpeinen (1986), Yearbook of Population Research in Finland of the Population Research Institute (several years), Yearbook of Nordic Statistics of the Nordic Council of Ministers (several years), and Demographic Yearbook of the United Nations (several years) were consulted.

Bongaarts (1978) developed a model which measures the decline of fertility in a society from its maximum biological level or total fedundity (TF) to the observed level or total fertility rate (TFR) in terms of four fertility-inhibiting indices $-\mathrm{C}_{m}$ (marriage), $\mathrm{C}_{\mathrm{c}}$ (contraception), $\mathrm{C}_{\mathrm{i}}$ (postpartum infecundability), and $\mathrm{C}_{\mathrm{a}}$ (abortion). The model is multiplicative and expresses the actual level of TFR as

$$
\begin{aligned}
& \mathrm{TFR}=(\mathrm{TFR} / \mathrm{TM})(\mathrm{TM} / \mathrm{TN})(\mathrm{TN} / \mathrm{TF}) \times \mathrm{TF} \\
& =\left(C_{m}\right)\left(C_{c} \times C_{a}\right)\left(C_{i}\right) \times T F \\
& 0 \leq \mathrm{TFR} \leq 15.3 \\
& 0 \leq \mathrm{C}_{\mathrm{m}}, \mathrm{C}_{\mathrm{c}}, \mathrm{C}_{\mathrm{a}}, \mathrm{C}_{\mathrm{i}} \leq 1 \text {, }
\end{aligned}
$$

in which TM is the total marital fertility rate and TN is the total natural marital fertility rate. The theoretical maximum of the TF is often assumed to have a mean value of 15.3, as suggested by Bongaarts. Each index is the ratio of the fertility level in the presence of, to the level in the absence of, the effect of the intermediate fertility variable (IFV). Thus, each index can assume values between 0 and 1 , inclusively, indicating complete to no reduction from total fecundity. Bongaarts' model and the fertility-inhibiting indices are presented in detail in Bongaarts (1978), Bongaarts and Potter (1983) and Hill (1985). 
Direct estimation of fertility-inhibiting indices using Bongaarts' model requires detailed data derived mainly from fertility and family planning surveys. However, as mentioned earlier, El-Khorazaty (1991), using data for 200 historical, developing and developed populations experiencing a wide range of fertility levels, found a very strong regression relation between the childbearing indices computed for the countries and the corresponding fertility-inhibiting indices. The resulting empirically derived multivariate regression model is

$$
\left[\begin{array}{l}
\hat{C}_{m} \\
\hat{C}_{c} \\
\hat{C}_{i}
\end{array}\right]=\left[\begin{array}{rrr}
.00044 & .00935 & .02120 \\
-.16726 & .19374 & -.17578 \\
.10295 & -.07639 & .08595
\end{array}\right]\left[\begin{array}{l}
\text { PAFB } \\
\text { PALB } \\
\text { PRLS }
\end{array}\right]
$$

Each regression equation has an $\mathrm{R}^{2}$ of at least $98.3 \%$ and a standard error not exceeding 0.10 . Since one of the main purposes of regression is prediction, and since the regressions have very high $\mathrm{R}^{2}$ values, the independent variables can certainly be used to predict or estimate values of the dependent variables. Thus, once the estimates of PAFB, PALB, and PRLS were obtained through the childbearing model, they were substituted into the regression model's equation to acquire estimates of the fertility-inhibiting indices $C_{m}$ (marriage), $C_{c}$ (contraception), and $C_{i}$ (postpartum infecundability) and their standard errors.

Substituting the estimates of the three projected childbearing indices, namely, PAFB, PALB and PRLS in the multivariate regression model (7), the three fertilityinhibiting (Bongaarts) indices were estimated for the period (1776-1987).

Availability of such long time series data made it possible to apply the Box-Jenkins technique (Box and Jenkins, 1976) in which multivariate causal models are developed, which consider correlation within and among variables over time. Experience and empirical applications of this technique suggest that it is preferable to any other single forecasting technique. Hence, forecasted childbearing indices were obtained. Justifications of applying time series methodology to demographic forecasting are discussed in Carter and Lee (1986) and Land and Cantor (1983). With only characterization but no theory regarding the childbearing transition (El-Khorazaty and Horne, 1992), time series models are appropriate, as they provide powerful analytical tools in such areas in which there exists little prior theory (McCleary and Hay, 1980).

Univariate Auto-Regressive Integrated Moving Average (ARIMA) models, referred to by ARIMA (p,d,q), of the childbearing indices, can conveniently be presented as:

$$
\Phi(B) \cdot(1-B)^{d} \cdot Y_{t}=\Theta(B) \cdot \varepsilon_{t}
$$

where $\varepsilon_{t}$ 's are independent, identically distributed normal random shocks with zero mean and variance $\sigma^{2}, \mathrm{~B}$ is the one-step backward shift operator such that $\mathrm{BY} \mathrm{Y}_{\mathrm{t}}=\mathrm{Y}_{\mathrm{t}-1}$, $\mathrm{d}$ is the degree of backward difference polynomial, and $\mathrm{Y}_{\mathrm{t}}$ is the projected childbearing index at time $t$. The auto-regressive and moving average polynomials are defined respectively as:

$$
\begin{aligned}
& \Phi(B)=1-a_{1} B-a_{2} B^{2}-\ldots-a_{p} B^{p}, \text { and } \\
& \Theta(B)=1-m_{1} B-m_{2} B^{2}-\ldots-m_{q} B^{q} .
\end{aligned}
$$

Univariate models for the three childbearing indices were identified, estimated and checked for adequacy and parsimony using time series data for the period (17761987). Successful modeling was followed by forecasting the designated series according to the model. Forecasts of each projected childbearing index, at this first stage, are functions only of their own past history. Forecastability of the models is tested by the generation of point forecasts and the calculation of interval forecasts. 
At the second stage, multivariate ARIMA, which show the patterns and interactions among both projected childbearing indices and four crude demographic variables, namely, crude birth rate (CBR), crude death rate (CDR), natural increase rate (NIR), and crude marriage rate (CMR) and infant mortality rate (IMR), were identified and estimated. These multivariate models help elucidate the dynamic relationship among these variables and improve the accuracy of the forecasts.

To identify the relationship between a crude demographic variable and a childbearing index, the "prewhitened» series (residuals) of the demographic variable series was obtained using the univariate model built in the first step. Then, the childbearing index series was filtered by the ARIMA model for the crude demographic variable series to obtain the filtered childbearing index series. The prewhitening method is advised for identifying an unknown dynamic system. Cross correlation functions between the prewhitened crude demographic variable series and the filtered childbearing index series was computed to help identify the functional form between the two variables, i.e., the transfer function component. Thus, the projected childbearing index, $\mathrm{Y}_{t}$, and the crude demographic variables, $\mathrm{Xi}_{\mathrm{t}}$ 's, $\mathrm{i}=1,2, \ldots, 5$, are linked by the multivariate relationship:

$$
\mathrm{Y}_{\mathrm{t}}=\Sigma_{\mathrm{i}}\left\{\left[\mathrm{U}_{\mathrm{i}}(\mathrm{B}) \div \mathrm{S}_{\mathrm{i}}(\mathrm{B})\right] \cdot \mathrm{Xi}_{\mathrm{t}}\right\}+\left[\varepsilon_{\mathrm{t}} \div \Phi(\mathrm{B})\right]
$$

where $\mathrm{U}_{\mathrm{i}}(\mathrm{B})=\left(\mathrm{U}_{\mathrm{i} 0}+\mathrm{U}_{\mathrm{i} 1} \mathrm{~B}+\ldots+\mathrm{U}_{\mathrm{ir}} \mathrm{B}^{\mathrm{r}}\right)$ and the S-polynomial has a form similar to the $\Phi$-polynomial.

Multivariate causal models relating each of the childbearing indices to various combinations of the four crude demographic variables (i.e., CBR, CDR, NIR, and CMR) and the IMR using time series data for the period (1776-1987) were identified, estimated and checked to arrive at parsimonious prediction equations. Data for these variables, aside from those on childbearing indices, come from Appendix B in Lutz (1987b), Mitchell (1981) and Demographic Yearbooks of the United Nations (several years). Variables which cause a reduction in the residual variance of the childbearing index, or the one-step-ahead forecasts generated by the model are those considered to be correlated with, and to help explain variations in, the index.

Using the identified univariate model for the CMR, the time series may be forecasted into the future. For the CBR, CDR, NIR, and IMR projected figures available from the United Nations (1989) were used. It is advisable to resort to statistical time series forecasting of independent crude demographic variables only when demographic projections are not available. Future values of the childbearing indices will be forecasted for the third period (1988-2022) using the fitted multivariate models and the forecasted values of the CMR and projected values of the CBR, CDR, NIR and IMR. Once the projected childbearing indices were forecasted, the three fertility-inhibiting indices were computed using the multivariate regression model (7).

Past values of the three projected childbearing indices, for the first period prior to 1776 , were estimated using reverse forecasting of the identified multivariate causal time series models and data available on the four crude demographic variables (CBR, CDR, NIR and CMR) since 1722, given in Appendix B in Lutz (1987b). Consequently, the three fertility-inhibiting indices were estimated using El-Khorazaty's multivariate regression model (7) for the period $1722-1775$.

The above methodology may be applied to countries which have a long time series of crude demographic variables, thus allowing a detailed diagnosis of reasons and mechanisms behind fertility and childbearing changes, in particular, and behind demographic transition, in general. Crude demographic variables are available for Sweden (since 1749), Norway (since 1795), Denmark and France (since 1800), Hungary (since 
1861), New Zealand (since 1875) and Canada (since 1900). Historical time series of macro-level childbearing and fertility-inhibiting indices may be, thus, calculated for such countries in a similar way.

\section{Results and discussion}

\section{Time series modeling and forecasting}

Annual estimates of temporal projected childbearing indices for the period 1776-1987 using available ASFRs, along with fertility-inhibiting indices, via the multivariate regression model (7), were obtained. The Box-Jenkins time-series technique, outlined in the previous section, was applied to the estimates of the projected childbearing indices (PAFB, PALB and PRLS), and the four crude demographic variables (CBR, CDR, NIR and CMR) and the IMR (called hereafter the five explanatory variables). Details of the modeling are shown in the Appendix. Only a summary of the results will be given here.

Parsimonious univariate ARIMA models for those eight measures were identified. All measures, except NIR and CMR, were differenced in order to obtain a stationary time series. Identified models were ARIMA $(1,1,0)$ for the PAFB, ARI$\operatorname{MA}(2,1,1)$ for the PALB, ARIMA $(1,1,2)$ for the PRLS, ARIMA $(0,1,1)$ for the CBR, $\operatorname{ARIMA}(0,1,2)$ for the CDR, $\operatorname{ARIMA}(2,0,0)$ for the NIR, $\operatorname{ARIMA}(1,0,0)$ for the CMR and ARIMA $(3,1,0)$ for the IMR. For models' specifications and statistics see the Appendix.

Next, investigations of the five explanatory variables, to find which variable or subset of variables contains information in past terms that helps in the prediction of the three childbearing indices, were conducted. Various combinations of the five explanatory variables were incorporated into the univariate models for the projected childbearing indices. The chosen final models, given in the Appendix, are those with smallest residual mean squares, which improves forecasting precision. The results show that the CBR, NIR and CMR cause changes in the three projected childbearing indices. Making use of projections available for crude demographic explanatory variables (United Nations, 1989) and the forecasted CMR, forecasts of the changes in childbearing temporal indices and determinants of these changes for the period 1988-2022 were computed. While it is not possible to forecast for a long period that extends to 35 years using univariate time series models, this is not the case herein. Multivariate models "account for the joint variation of several social indicators and, based on this structure, will give reliable long-range forecasts» (McCleary and Hay, 1980). In addition, an increased understanding of and considerably more information on the childbearing-demographic system can be gained from conventional macro-level material.

To extend our view of the Finnish childbearing and fertility history back to 1722 , using the same multivariate time series models that described the nature of change during $1776-1987$, reverse forecasts of the three projected childbearing indices were estimated. Consequently, fertility-inhibiting indices for the same period also were computed through regression model (7).

Table 1 (see pp 60-65) shows the results of the proposed methodology for Finland for the period (1722-2022). Projected indices for various aspects of timing of childbearing and determinants of fertility changes provide more detailed information about the dynamics of aggregate fertility changes than can the crude demographic rates or period total fertility rates (TFRs) alone. Similar levels of TFR may have differ- 
ent childbearing temporal indices (PAFB, PALB, and PRLS) and different fertilityinhibiting indices $\left(\mathrm{C}_{\mathrm{m}}, \mathrm{C}_{\mathrm{c}}, \mathrm{C}_{\mathrm{j}}\right)$. Variations in the timing of childbearing might occur with no or little change in the level of completed fertility. Additional indices such as projected mean inter-birth spacing and proportion of childless women may be computed from the three projected childbearing indices (for details see Horne, El-Khorazaty and Suchindran, 1990). While the childbearing indices are projected indices, since they refer to an waverage» woman using the childbearing model equations for estimation, they will be referred to hereafter without the word projected for simplicity. The two sets of indices should provide new insights into Finnish childbearing, fertility and marriage experience across time since 1722 by making informative use of a 212 single-year period of ASFRs and 266 years of crude demographic measures, including 1722 - 1775 data, that have been subjected to little previous analysis.

Model estimates of TFR may be calculated using fertility-inhibiting indices presented in Table 1 and equation (6). However, the use of 15.3 births as an estimate of total fecundity (TF) should be reconsidered. During the first part of the eighteenth century, the mean life expectancy at birth in Finland, as in other pre-industrial European countries, was at best in the mid-thirties (only 27 years for 1806-10 and 1866-70, as estimated by Mielke et al., 1987) and increased very slowly until the late nineteenth century, when the value was around the mid-forties. Women then were exposed to the risk of pregnancy for not more than 20 years, on average, during the eighteenth century. Assuming the same average incidence of sterility (17\% of potential reproductive years) proposed by Henry (1961) and adopted by Bongaarts (1978), and the typical mean birth interval in the absence of lactation (20 months), then on the macro-level, an average of only ten births per woman for the TF is obtained. Model TFR estimates should be then about $65 \%$ of their estimated values (10/15.3), using the fertility-inhibiting indices shown in Table 1 and the TF of 15.3 births. This percentage should increase gradually because of the increase in the expectation of life during the late nineteenth century.

In addition, because of wars, famines, plagues and epidemics which were observed during these two centuries, couples were separated for lengthy periods. Lutz and Pitkänen (1986) state that »due to the continuous wars considerable proportions of the young male population were drafted,» and thus were away from their wives for prolonged periods of time. To capture this effect on fertility, Hill (1985) suggested an index of spousal separation, $\mathrm{C}_{\mathrm{s}}$, which requires data on prevalence by age. While this factor should be taken into consideration even until the mid-twentieth century, due to the two world wars, the Civil War of 1918, the Winter War of 1939-40, emigration to the U.S. in the 1900 s and 1910 s and to Sweden in the 1950 s and 1960 s, and other critical/abnormal situations, no data on separation are available for Finland. Accordingly, the conservative percentage of $65 \%$ may be applied during these unusual periods if one is interested in obtaining model estimates of TFR. When a TF value of 10 was used, observed TFRs were found to be within a $95 \%$ or, at worst, within a $99 \%$ confidence interval of the TFR estimates, using the described indirect methodology, for the period since 1776 until the mid-twentieth century.

A quick test of the validity of the indirect methodology may be done by comparing the results depicted in Table 1 with those using the direct methodology suggested by Bongaarts (1978). This is possible only for the year 1971, for which Bongaarts' model estimate of the TFR was 1.11 (Bongaarts and Potter, 1983), while the estimate using the present methodology and the regression model (7) was 1.28 . The observed TFR for 1971 was 1.61. Estimates of $C_{m}, C_{c}$ and $C_{i}$ are $0.514,0.171$ and 0.930 , respectively, using Bongaarts' direct methodology, and $0.463,0.186$ and 0.969 , respectively, using the indirect methodology. In addition, observed TFRs are within 
the $95 \%$ level confidence intervals of the model TFR estimates, using the methodology described herein for the years since the mid-1950s.

\section{The Childbearing and Fertility-inhibiting Process Since 1722}

\section{The recovery: the period until the mid-eighteenth century}

At the end of the Great Northern War in 1721, fertility started to recover from the probable low levels during the first two decades of the eighteenth century, resulting from the 1710-11 epidemic and the years of crop failure and great famine at the end of the seventeenth century, as reflected in the increase in the CBR from 30.2 per thousand in 1722 to the low forties in the late 1730 s. This increase in the CBR, and simultaneously in the marriage index $\left(\mathrm{C}_{\mathrm{m}}\right)$, during this period happened in spite of the decrease in the registered crude marriage rates (CMRs) from 12.2 per thousand in 1722 to $7-8$ in the late 1730 s. The fertility recovery depended a great deal on older women, as projected ages at last birth (PALB) increased from 32.1 years in 1722 to around 35.6 - 36.8 for the years $1739-41$, while an overall increasing trend was observed in ages at first birth (PAFBs) from around 20.5 years during the mid-1720s to only about 22 years in the late 1730 s. The later age pattern of entry into childbearing in the 1720 s implies the prevalence of an early age pattern of marriage in the first decades of the eighteenth century. Low figures for ages at last birth in the early eighteenth century were because of short life spans, which should have been only around the mid-thirties. Increases in ages at last birth probably coincided with the gradual but slow rise in the life expectancy.

Changes occurring in the entry into and exit from the childbearing process resulted in longer reproductive life spans (PRLSs), from 11.5 years in 1722 to around 14 to 15 years for the years $1739-41$. Accordingly, the »baby boom» which occurred after the end of the Great Northern War was not a result of universal marriage or a change in marriage pattern, but was mainly due to the increase in marital fertility, by later ages at childbearing and longer reproductive life spans, and lower rates of use of fertility control (increase in the values of the contraception index, $\mathrm{C}_{\mathrm{c}}$ ). This result indicates that, at an earlier time in the eighteenth century, fertility limitation by means other than late and nonuniversal marriage existed - however, playing only a small role - and had an effect on the fertility level. Andorka (1978) proves that folk methods of contraception and induced abortion were widely known in almost all societies and in almost all historical periods. While fertility in Finland never reached any level near its biological maximum, the justification given for Sweden by Breckenridge (1983) that this was because of madoption of Malthusian control of fertility - postponement of marriage, and maintenance of never-married status» needs to be amended for the case of Finland. The above analysis suggests that practices of family limitation to limit the number of births were also responsible, at least in part, for relatively low fertility levels earlier in the eighteenth century, and resulted in an earlier termination of the reproductive period, with an average age at last birth of only about 32 years in 1722 and a contraception index of 0.7 .

This recovery came to an end with the start of the War of the Hats in the early 1740s. During the years $1740-43$, the CBRs decreased while CDRs increased sharply, resulting in negative population growth rates. Reproductive life spans were shortened by almost three years in two years' time, from 15.2 years in 1741 to only 12.5 years in 1743, as a result of the combined effects of increased ages at first birth and decreased ages at last birth. The increased role of family limitation (decreased values of the contraception index, $\mathrm{C}_{\mathrm{c}}$ ) is also evident during the war period and is probab- 
ly responsible for younger ages at last birth and early termination of childbearing. The crude marriage rate registered its lowest value of only 6 per thousand in the years $1741-42$, and the marriage index, $C_{m}$, reached its highest value of 0.68 in 1741 . In addition, the youngest value for age at first birth of only 20.7 years was observed for the year 1741, after which it started to increase gradually. Lutz (1987b) confirms these results. He speculates that high mortality proportions during the War of the Hats "probably led to ... a shortage of rural labor force ... and to an increased possibility for the young generation to take over their parents' farms at a younger age. This may have led temporarily to younger mean ages at marriage [and consequently, younger ages at first birth] and the higher proportions ever-married.» The effect of the end of the war in 1744 was reflected in the childbearing indices in the following year. Ages at first birth decreased by one year, and ages at last birth increased by 1.3 years, resulting in a lengthening of the reproductive life span by 1.5 years.

The overall increasing trend in ages at first birth during the period $1722-1740$ (and beyond until the late eighteenth century), in spite of fertility increase, could be an indication of a Malthusian transition from universal and early marriage in the seventeenth century to late marriage and a high proportion remaining unmarried, which Coale (1974) called the first demographic transition in Europe. Hajnal (1965) speculates that this marriage transition might have to do with the Reformation and its consequences on parish registration and voluntary agreement of spouses. In addition, young people often circulated before marriage between households as servants (Hajnal, 1983). The implication for marriage transition from childbearing transition is only valid for this period, since illegitimacy (only $1.26 \%$ in 1751) and fertility control were negligible and the start of a union indicated an intention to have children soon.

\section{Abrupt transition and relative stability: the period between the mid-eighteenth century and the end of the nineteenth century}

The highest recorded CBRs of around 45 per thousand were observed in the $1750 \mathrm{~s}$ and early $1760 \mathrm{~s}$, while CMRs declined gradually from around 11 in the early $1750 \mathrm{~s}$ to about 8 in the mid 1760 s. These changes were reflected in increased ages at first birth, from 22.4 in 1751 to about 24 years in $1762-63$. The ages increased very slowly afterwards to reach around 25 years in the early part of the twentieth century. Increases in PAFBs were a direct consequence of postponement of marriage, since »for $1751-1775$ the female modal age at marriage was 19 and ... [the period $1776-1800$ shows] a dramatic increase in modes, raising the estimation of the female modal age at marriage to 23 ,» (Lutz, 1987b). In the ensuing decades, ages at first birth increased slightly from 24.5 years in the early nineteenth century to about 25.5 years one century later. This increase can be attributed to $»$ the rising average age at first marriage, which shortened the fertile period, [and] was one reason for the declining birth rate during the pre-industrial period» (Finland, Central Statistical Office, 1975).

Figure 1 reveals that ages at last birth increased from 37 years in the late $1740 \mathrm{~s}$ and early 1750 s, to reach a high of 40.6 years in 1770 , and declined again to about 39 years in the late 1780s. Ages at last birth stabilized afterwards at around 39-40 years until the early 1900 s.

Age at last birth is considered as sthe most straightforward measure reflecting attempts to deliberately stop childbearing prior to the end of the reproductive age span» (Knodel, 1987), and it is a preferred index to study the extent of fertility control (Ewbank, 1989). The decline in PALBs during the 1770 s and 1780 s suggests that 
Figure 1. Three centuries of childbearing indices in Finland (1722-2022)

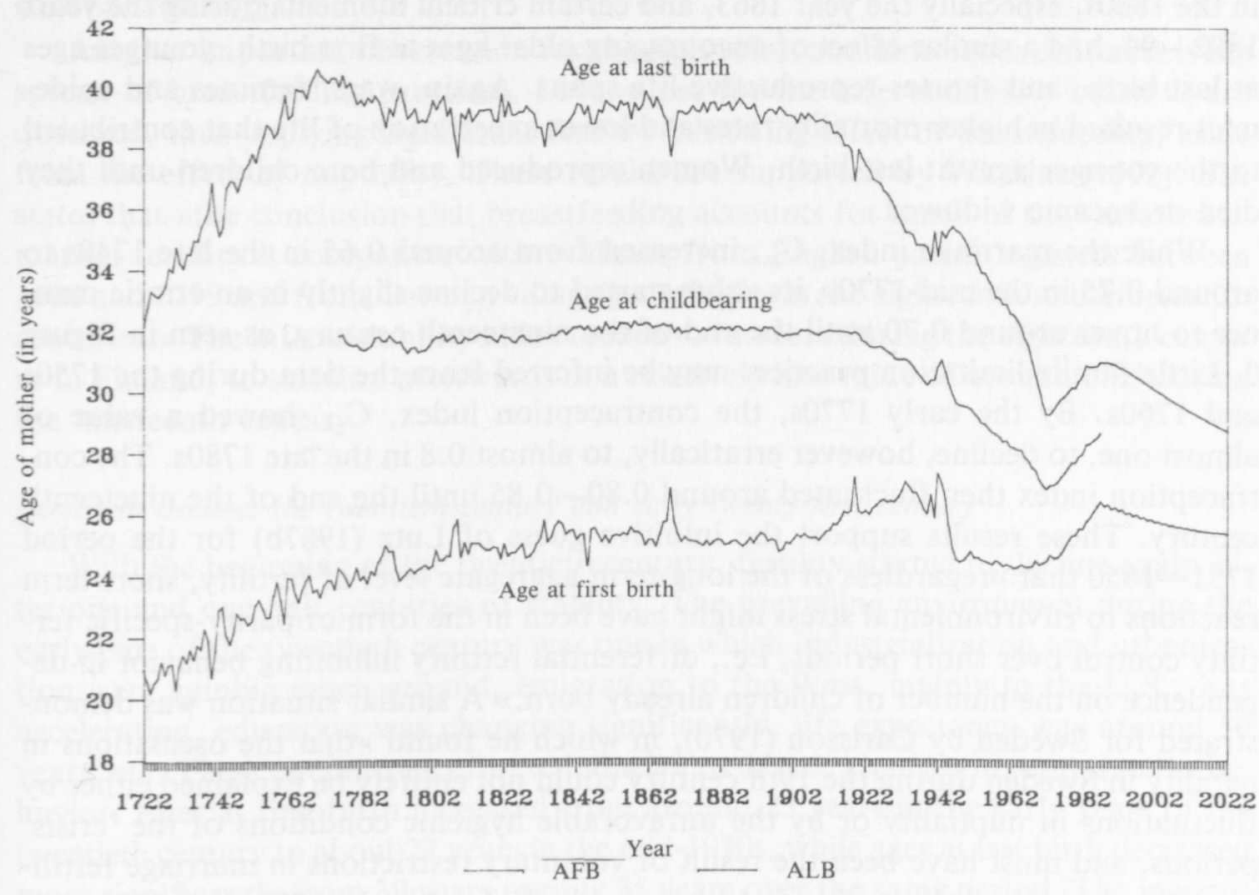

the early fertility transition could be interpreted as a change in marital fertility, as well as nuptiality, and that deliberate fertility control was practiced. This conclusion has been supported by some authors (Kaukiainen, 1973 and Turpeinen, 1978) and opposed by others (Lutz, 1987a). Experiences of German villages in the eighteenth and nineteenth centuries suggested a similar point that »couples were increasingly adopting a stopping strategy for controlling fertility ... through which marital fertility came under volitional control and is the major feature of reproductive change during the initial phases of the fertility transition,» (Knodel, 1987). One should remember that female expectation of life at birth was only around 41 years in the mid-eighteenth century and fluctuated in the neighborhood of $40-45$ years until the mid-nineteenth century. This caused the length of the reproductive life span to reach a heighth of around 17 years in the early 1770 s, to shorten gradually to about 15 years in the early 1790 s and then slowly to about 14 years by the first decade of the twentieth century.

Departures from these general trends in reproductive behavior during this one and one-half century of stabilization can be examined in relation to singular events which are expected to have large, although temporary, effects on childbearing patterns, as seen in Figure 1. During the 1789-91 war, age at first birth increased to about 25 years in 1789 , while age at last birth declined to about 38.6 years, thus shortening the reproductive life span to only 14.4 years. The War of Finland had its effect on the age at first birth, increasing it to 25.8 in 1809 , and on the age at last birth, decreasing it to 37.7 for the same year; hence, a reproductive life span of only 13 years is observed. These changes in childbearing indices were reversed in the ensuing years after the 1808-1809 War, as a result of a marriage boom and a catch-up period in fertility, as mentioned by Mielke and Pitkänen (1989). 
The Cholera epidemic in the mid-1830s, the several successive years of famine in the 1860 s, especially the year 1863 , and certain critical moments during the years 1892 - 94, had a similar effect of encouraging older ages at first birth, younger ages at last birth, and shorter reproductive life spans. Again, wars, famines and epidemics resulted in higher mortality rates and lower expectation of life that contributed to the younger ages at last birth. Women reproduced and bore children until they died or became widowed.

While the marriage index, $\mathrm{C}_{\mathrm{m}}$, increased from around 0.65 in the late 1740 s to around 0.75 in the mid-1770s, its value started to decline slightly in an erratic manner to hover around 0.70 until the end of the nineteenth century, as seen in Figure 2. Little family limitation practices may be inferred from the data during the $1750 \mathrm{~s}$ and $1760 \mathrm{~s}$. By the early $1770 \mathrm{~s}$, the contraception index, $\mathrm{C}_{\mathrm{c}}$, showed a value of almost one, to decline, however erratically, to almost 0.8 in the late $1780 \mathrm{~s}$. The contraception index then fluctuated around $0.80-0.85$ until the end of the nineteenth century. These results support the intuitive guess of Lutz (1987b) for the period $1751-1850$ that $»$ regardless of the long-term aggregate level of fertility, short-term reactions to environmental stress might have been in the form of parity-specific fertility control over short periods, i.e., differential fertility inhibiting behavior in dependence on the number of children already born." A similar situation was demonstrated for Sweden by Carlsson (1970), in which he found sthat the oscillations in natality in Sweden during the 19th century could not entirely be explained either by fluctuations in nuptiality or by the unfavorable hygienic conditions of the 'crisis' periods, and must have been the result of voluntary restrictions in marriage fertility.» The short-lived decreasing fertility trend in Finland in the 1770 s and 1780s, ac-

Figure 2. Fertility-inhibiting indices in Finland (1722-2022)

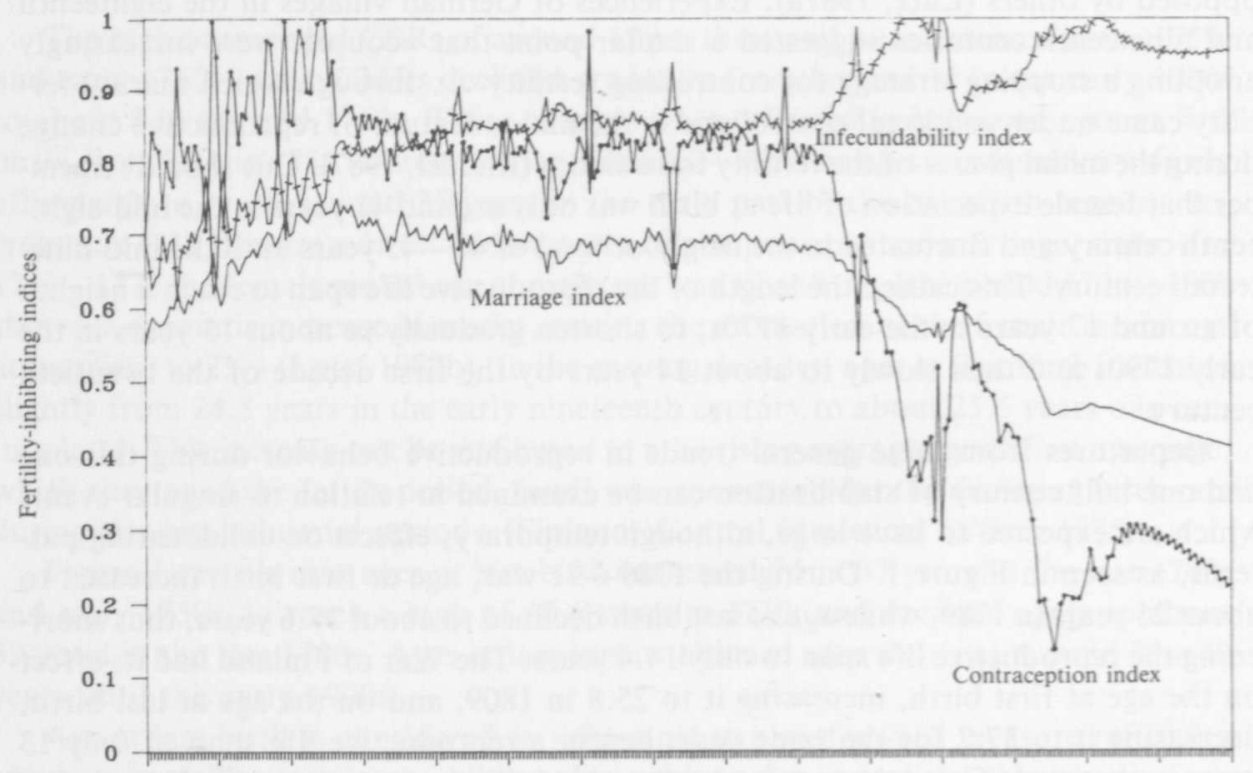

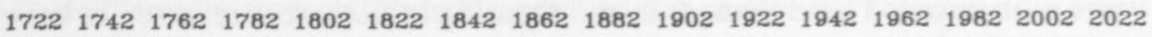

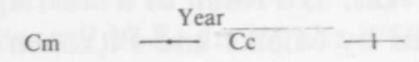


cordingly, was due mainly to both changes in nuptiality and reproductive behavior (marital fertility).

Another important observation for the eighteenth and nineteenth centuries is the spread of breastfeeding practices. Low values for the infecundability index $\mathrm{C}_{\mathrm{i}}$ are observed, thus implying significant fertility inhibiting effect of breastfeeding, aside from the effect of nuptiality. These results are supported by Watkins (1990). She states that "the conclusion that breastfeeding accounts for much of the variation in marital fertility is compatible with evidence from English parish registers between 1600 and 1799 and from German village genealogies in the eighteenth and nineteenth centuries.» The infecundability index tended to increase during the eighteenth century in Finland, to stabilize afterwards at a relatively low value of around 0.85 during the nineteenth century.

\section{Persistent decline: the twentieth century and early twenty-first century}

With the beginning of the twentieth century, fertility started to decline again after one and one-half centuries of stability. The prevailing environment during the early part of the twentieth century was one in which industrialization and urbanization were gaining much ground, emigration to the West, mainly to the U.S., was accelerating, education was changing significantly, life expectancy was around 50 years, etc. These circumstances were inducive to drastic changes in reproductive behavior. Ages at first birth increased from around 25 years in the early years of the twentieth century to about 27 years in the mid-1930s, while ages at last birth decreased more significantly from 39 years to only 35 years over the same period. The increasingly younger childbearing pattern was more dramatic after the year 1910 .

These results confirm other observations regarding the reproductive behavior in Western countries, which indicate that »the decline in fertility primarily and particularly affects the end of the reproductive period, before extending gradually to affect the youngest age groups» (Festy, 1984). Women's exposure to the risk of pregnancy, measured by the length of reproductive life spans, decreased substantially from almost 15 years to about 11 years during the first one-third of the twentieth century. The disruption occurred mainly during the year of epidemics in 1919. The years of the First World War (1914-1918) did not have a significant effect on the fertility and childbearing process in Finland, other than general trends observed since 1910. The expected depressing effect of the War on fertility and reproductive behavior might have been offset by the growth of nationalist pronatalist sentiments prevailing since the nineteenth century.

The fertility decline during the period 1900 - 1935, which gained momentum after 1910 , is implied by the changes in fertility-inhibiting indices. While the marriage index did not change very much during the first decade of the twentieth century and hovered around 0.68 , its value declined sharply to only 0.57 by the mid-1930s. Similarly, the contraception index, which was around 0.81 during the first decade, declined drastically to 0.38 by the mid-1930s. Increases in the postpartum infecundability index to its maximum value of one during the mid-1930s imply virtually no breastfeeding practices and, consequently, no inhibiting effect on fertility. Fertility transition during the first one-third of the twentieth century, or, in particular, during the 25-year period succeeding 1910, was due mainly to changes in reproductive behavior and marital fertility as a result of the widespread use of contraceptives. The neo-Malthusian transition through the reduction of marital fertility was stressed by Coale (1974) when discussing the second demographic transitions in Europe. Changes in marriage patterns and breastfeeding practices played a relatively minor role, compared to their 
role in the demographic transitions of the two periods from 1722 to 1750 s and during the 1770 s and 1780 s.

Irregular fluctuations in childbearing and fertility-inhibiting indices that accompanied fertility changes were the characteristics of the period 1935-45. This period experienced several short-term fluctuations due to the two phases of the Winter War (1939 - 40 and 1941 -44) and the Second World War (1939-45).

The period immediately after World War II was affected by postwar changes and the baby boom. Ages at last birth increased to above 35 years in 1946-49, while ages at first birth declined to around 24.5 in the same period. However, the longrange trend which started in 1910 and was interrupted in the mid-1930s was restored from the late 1940s until the early 1970s. These trends are a logical continuation of the demographic transition during the period $1910-35$, and were obviously a consequence of the same structural changes, such as large internal migration, rapid urbanization and industrialization. Irregularities in childbearing indices during the war years and the baby boom phenomenon afterwards should be regarded as departures from the general trends which prevailed since the early twentieth century.

Age at last birth started to decline sharply since the late 1940 s to reach only 29.5 years in the mid-1970s, while the low level of age at first birth persisted during this period, showing very little change in the timing of entry into childbearing. Length of the reproductive life span fell by four years, from 12 years in the mid-1940s to 8 years in the mid-1970s. The year 1973 witnessed the smallest birth cohort since the famine years of the 1860 s. The main fertility-inhibiting index responsible for the decline in fertility during the period $1946-75$ was contraception, in which its index decreased dramatically from around 0.60 in the mid-1940s to a low of 0.14 in 1973 , increasing slightly afterwards.

After the mid-1970s, age at last birth started to increase gradually, reversing the persistent declining trend observed in the early years of the twentieth century, to reach 31 years during the mid-1980s. Similarly, age at first birth increased systematically to reach in the late 1980 s the level prevailing in the mid-1930s. These trends were observed also in Western Europe, in which »the period of most rapid fall [in fertility] ceased around 1975 and some small rises have since taken place ... [and] after a long phase towards younger childbearing, a reversal trend has taken place,» (Calot and Blayo, 1982). The length of the reproductive life span was generally stable during the 1970 s and 1980 s. These trends indicate a changing pattern of marriage since the mid-1970s towards later age at marriage and/or postponement of the birth of the first child, while keeping the length of the reproductive life span unchanged, resulting in stable TFRs of around 1.7 births.

Multivariate time series forecasting indicates that a downward trend in projected ages at first and last birth is expected. However, reproductive life spans will tend to decrease from almost 8 years in the late 1980 s to a little above 6 years in the early 2020 s, as a result of a faster rate of decline in ages at last birth compared to ages at first birth. It is forecasted that ages at first birth will decline to about 25.5 years in the early 2020 s, while ages at last birth will be just below 29 years for the same period. These trends are conditioned on the projections of the United Nations (1989), which show declining CBRs and increasing CDRs, thus resulting in declining NIRs in the next three decades. Both marriage and contraception indices are expected to decline, implying prospective changes in nuptiality patterns as well as the childbearing process. The next few decades will tell if the upward trend observed in ages at first and last birth during the period $1975-87$ will continue, and whether it will be a long-term phenomenon or a short-term fluctuation to be reversed. Both indices 
cannot continue to increase simultaneously, since there are societal and biological restrictions. It remains to be seen how long this upward trend will continue before leveling off or being reversed.

\section{Concluding remarks}

Aggregate, macro-level childbearing and fertility-inhibiting indices presented in this study, even with the increasing availability of micro-level data, are clearly informative and can open new directions in historical demography and the study of the dynamics of change in demographically interpretable indices. The justification of using macro-level measures are best expressed by Breckendridge (1983). She states that mmeasures of the aggregate consequences of individual behaviors continue to have a central place in demographic analysis for several good reasons: . . . to identify population trends and transitions; ... . [and] to permit the comparison of current patterns with historical patterns in those populations for which more detailed information is not available.» Although the primary contribution of this paper is to use a recently introduced methodology to produce temporal childbearing and fertility indices, which relies only on quantum aggregate data, rather than to study Finnish history, this paper nevertheless provides new insights into nuptiality and childbearing processes in Finland across three centuries. Diverse events and changing characteristics in Finland during this period, such as varying age patterns of marriage and occurrences of wars, severe crop failures and periods of high migration, are expected to affect childbearing levels and patterns. In addition, changes in fertility have been analyzed by different methodologies and analytic approaches, thereby providing means of evaluating the results from the methodology used herein.

The results presented in this paper demonstrate that Finland passed through three demographic transitions. The first was mainly a nuptiality transition (1720-1760), while the second was a nuptiality/childbearing transition (1770 - 1790) and the third, essentially a childbearing transition (1910-1985). A stabilization in the childbearing and fertility process was observed during the nineteenth century. While the period until the late eighteenth century was characterized mainly by nuptiality transition, the stabilization period, between the late eighteenth century and the beginning of the twentieth century, corresponds to stage I of the childbearing transition characterization (CTC), introduced by El-Khorazaty and Horne (1992). In stage I, nuptiality patterns were essentially stable, both ages at first and last birth were high, resulting in reproductive life spans relatively short (about 15 years) and fertility not as high when compared to today's developing countries.

The twentieth century childbearing experience until the mid-1970s corresponds to stage II of the CTC, in which ages at last birth declined at a faster rate, while ages at first birth increased slightly. Thus, reproductive life spans decline sharply. The reduction in family size occurring in this stage is the result of changes in the knowledge and acceptability of contraception, which play an essential part in earlier termination of childbearing and low population growth rates.

Since the mid-1970s, increases in both ages at first and last birth resulted in reproductive life spans being stable in the range of $6-8$ years, corresponding to stage III of the CTC. The decrease in childbearing at younger ages is fully offset by an increase at higher ages, so that the average number of births per woman remains the same. Childbearing changes during this period were a matter of timing. The shift in age distribution of fertility towards older ages and, thus an older childbearing pattern in recent years, is a result of the prominent influence of change in crude mar- 
riage rates since the late 1950 s, when the CMR increased from only 7.2 in the years $1957-59$ to almost 9 in the early 1970 s, before starting to decline again to a low of 5.3 in the late $1980 \mathrm{~s}$.

Further insights into childbearing-demographic-socioeconomic mechanisms may be gained if childbearing-demographic multivariate time series causal models developed herein are extended to consider societal socioeconomic indicators and other intervening fertility-inhibiting variables. The results of such causal modeling can aid in the development of a theory of the childbearing transition. Future works should take advantage of the availability of long time series data on the requisite covariate data. Lutz $(1987 \mathrm{a}, \mathrm{b})$ asserts that the case of Finland shows that socioeconomic factors did not affect the fertility development to any great extent and that reproductive behavior was a reflection rather of individual mentality and culture. However, the application of time series techniques for several countries at different stages of the demographic transition is needed first in order to cover various phases of development before reaching a final conclusion on this issue. Moreover, childbearing and fertility-inhibiting indices presented herein are more sensitive reflections of changes in fertility patterns and socioeconomic changes in the society than crude demographic variables, total fertility rates, and the mean age at childbearing, usually used in such analyses.

\section{Appendix}

\section{Time series forecasting models}

First: Univariate Models

The Box-Jenkins auto-regressive integrated moving-average ARIMA (p,d, $q$ ) models are represented by equation (8), in which $\mathrm{p}$ and $\mathrm{q}$ are the degree of the auto regressive and moving average processes, respectively, and $\mathrm{d}$ is the degree of differencing. For the five explanatory demographic variables and the three temporal childbearing indices the auto-correlation function and the partial autocorrelation function were inspected and the series was differenced if it revealed nonstationarity. Accordingly, parsimonious models were identified and estimated. The following are the estimated models along with their summary statistics.

(1) The CBR: ARIMA $(0,1,1)$

$\mathrm{m}_{1}=0.429$, s.e. $\left(\mathrm{m}_{1}\right)=0.062$

Residual mean squre $=4.817, \mathrm{df}=209$

(2) The CDR: ARIMA $(0,1,2)$

$\mathrm{m}_{1}=0.508$, s.e. $\left(\mathrm{m}_{1}\right)=0.064$

$\mathrm{m}_{2}=0.363$, s.e. $\left(\mathrm{m}_{2}\right)=0.065$

Residual mean square $=34.006, \mathrm{df}=208$

(3) The NIR: $\operatorname{ARIMA}(2,0,0)$

$a_{1}=0.650$, s.e. $\left(a_{1}\right)=0.069$

$a_{2}=0.153$, s.e. $\left(a_{2}\right)=0.068$

Residual mean square $=0.627, \mathrm{df}=207$

(4) The CMR: ARIMA(1,0,0)

$a_{1}=0.975$, s.e. $\left(a_{1}\right)=0.007$

Residual mean square $=0.768, \mathrm{df}=209$

(5) The IMR: $\operatorname{ARIMA}(3,1,0)$

$a_{1}=-0.668$, s.e. $\left(a_{1}\right)=0.047$

$a_{2}=-0.512$, s.e. $\left(a_{2}\right)=0.053$

$a_{3}=-0.59 i$, s.e. $\left(a_{3}\right)=0.041$

Residual mean square $=318, \mathrm{df}=114$ 
(6) The PAFB: ARIMA $(1,1,0)$

$a_{1}=-0.243$, s.e. $\left(a_{1}\right)=0.067$

Residual mean square $=0.103, \mathrm{df}=208$

(7) The PALB: ARIMA $(2,1,1)$

$a_{1}=0.691$, s.e. $\left(a_{1}\right)=0.101$

$a_{2}=0.292$, s.e. $\left(a_{2}\right)=0.066$

$\mathrm{m}_{1}=0.958$, s.e. $\left(\mathrm{m}_{1}\right)=0.085$

Residual mean square $=0.115, \mathrm{df}=205$

(8) The PRLS: ARIMA(1,1,2)

$a_{1}=-0.907$, s.e. $\left(a_{1}\right)=0.086$
$m_{1}=-0.640$, s.e. $\left(m_{1}\right)=0.099$
$m_{2}=0.294$, s.e. $\left(m_{2}\right)=0.068$

Residual mean square $=0.173, \mathrm{df}=206$

Second: Multivariate Models

To estimate multivariate causal time series models, cross correlation functions between each childbearing index and the five explanatory variables are calculated using the differenced series, when necessary. Various combinations of the prewhitened series of the five explanatory variables were obtained and the univariate models for each childbearing index were filtered. A cross correlation function was then computed in order to identify the transfer function model. The following are the estimated multivariate models along with their summary statistics. A reduction in the residual mean square error is observed, compared to the univariate models.

(1) The PAFB:

$$
\begin{aligned}
(1-\mathrm{B}) . \mathrm{PAFB}_{\mathrm{t}}= & {[(-0.1295+0.1322 \mathrm{~B}) /(1-0.1385 \mathrm{~B})](1-\mathrm{B}) \cdot \mathrm{CBR}_{\mathrm{t}} } \\
& +[(-0.002817-0.04396 \mathrm{~B}) /(1-0.1925 \mathrm{~B})] . \mathrm{NIR}_{\mathrm{t}} \\
& +[(-0.01863+0.00473 \mathrm{~B}) /(1+0.9549 \mathrm{~B})] . \mathrm{CMR}_{\mathrm{t}} \\
& +\left[(1-0.1676 \mathrm{~B}) \cdot \varepsilon_{\mathrm{t}}\right.
\end{aligned}
$$

Residual mean square $=0.0246$, $\mathrm{df}=200$

(2) The PALB:

$$
\begin{aligned}
(1-\mathrm{B}) . \mathrm{PALB}_{\mathrm{t}}= & {[(0.1418-0.1382 \mathrm{~B}) /(1-0.03222 \mathrm{~B})](1-\mathrm{B}) \cdot \mathrm{CBR}_{\mathrm{t}} } \\
& +[(-0.01126+0.08264 \mathrm{~B}) /(1+0.6175 \mathrm{~B})] . \mathrm{NIR}_{\mathrm{t}} \\
& +[(-0.02473) /(1+0.03044 \mathrm{~B})] \mathrm{CMR} \mathrm{R}_{\mathrm{t}} \\
& +\left[(1-0.5938 \mathrm{~B}) /\left(\left[\left(1-0.4635 \mathrm{~B}-0.2606 \mathrm{~B}^{2}\right)\right] . \varepsilon_{\mathrm{t}}\right.\right.
\end{aligned}
$$

Residual mean square $=0.0276, \mathrm{df}=197$

(3) The PRLS:

$$
\begin{aligned}
(1-\mathrm{B}) . \mathrm{PRLS}_{\mathrm{t}}= & {[(0.1748-0.1737 \mathrm{~B}) /(1-0.1427 \mathrm{~B})](1-\mathrm{B}) \cdot \mathrm{CBR}_{\mathrm{t}} } \\
& +[(0.03482+0.04534 \mathrm{~B}) /(1+0.6394 \mathrm{~B})] . \mathrm{NIR}_{\mathrm{t}} \\
& +[(-0.02447+0.000883 \mathrm{~B}) /(1+0.8648 \mathrm{~B})] . \mathrm{CMR}_{\mathrm{t}} \\
& +\left[\left(1-0.6937 \mathrm{~B}+0.2576 \mathrm{~B}^{2}\right) /(1-0.1512 \mathrm{~B})\right] . \varepsilon_{\mathrm{t}}
\end{aligned}
$$

Residual mean square $=0.0262, \mathrm{df}=197$ 
CHILOBEARING AND FERTILITY-INHIBITING INDICES IN FINLAND $(1722-2022)$

\begin{tabular}{|c|c|c|c|c|c|c|}
\hline \multirow[b]{3}{*}{ YEAR } & CHILDBEA & RING INDICES & & $80 \mathrm{H}$ & AARTS & ES \\
\hline & AFB (years) & ALB (years) & PRLS & MARRIAGE & CONTRACEPTIOK & INFECUMDABILITY \\
\hline & Mean s.e. & Hean s.e. & 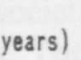 & co & Cc & $\mathrm{Ci}$ \\
\hline
\end{tabular}

\begin{tabular}{|c|c|c|c|c|c|c|c|c|c|c|c|}
\hline & & & & 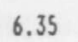 & & 0.553 & 0.014 & 0.696 & 0.016 & 0.693 & \\
\hline & .60 & 5.63 & 32.75 & 6.35 & 12.18 & 0.573 & 0.016 & 0.758 & 0.019 & 0.666 & 30 \\
\hline & 20.20 & 5.63 & 33.29 & 6.35 & 12.68 & 0.589 & 0.021 & 0.842 & 0.025 & 0.626 & \\
\hline & 20.52 & 5.63 & 33.15 & 6.35 & 12.35 & 0.581 & 0.020 & 0.819 & 0.024 & 642 & 026 \\
\hline & 20.66 & 5.63 & 33.09 & 6.35 & & 577 & 0.021 & 0.814 & 0.024 & 0.646 & \\
\hline & 21.22 & 5.63 & 33.22 & 6.35 & & 579 & 0.014 & 0.737 & 0.017 & 0.698 & 018 \\
\hline & 20.79 & 5.63 & 3.47 & 6.35 & 12.55 & 588 & 0.018 & 0.801 & 0.022 & 0.662 & \\
\hline & 21.10 & 5.63 & 4.04 & 6.35 & 13.01 & .603 & 0.015 & 0.179 & 0.018 & 0.690 & \\
\hline & 21.15 & .63 & 3.93 & 6.35 & .91 & .600 & 0.014 & 0.767 & 0.017 & 0.695 & 018 \\
\hline & 20.31 & 5.63 & 34.72 & 6.35 & 13.63 & 0.623 & 0.025 & 0.934 & 0.030 & 0.610 & 032 \\
\hline & 21.09 & 5.63 & 34.20 & 6.35 & 12.93 & 0.603 & 0.019 & 0.826 & 0.022 & 0.670 & .024 \\
\hline & 21.42 & 5.63 & 34.03 & 6.35 & 12.57 & 94 & 0.018 & 0.801 & 0.021 & & 023 \\
\hline & 21.19 & 5.63 & 34.50 & 6.35 & 13.19 & 612 & 0.018 & 0.821 & 0.021 & & 027 \\
\hline & 21.62 & 5.63 & 34.47 & 6.35 & & & .016 & 0.789 & 0.019 & 0.704 & 020 \\
\hline & 21.28 & 5.63 & 34.95 & 6.35 & & 624 & .016 & 0.823 & 0.019 & 0.689 & 021 \\
\hline & 21.76 & 5.63 & 4.92 & 6.35 & 13. & 6 & 0.016 & 02 & 0.019 & 0.709 & 020 \\
\hline & 21.61 & 5.63 & 35.36 & 6.35 & 13. & 0.635 & 0.013 & 0.793 & 0.015 & 0.718 & 016 \\
\hline & 22.30 & 5.63 & 35.63 & 6.35 & 14. & $0.64:$ & 0.007 & 0.705 & 0.009 & 0.781 & 009 \\
\hline & 21.92 & 5.63 & 35.93 & 6.35 & 14.2 & 0.6 & 0.012 & 90 & 0.014 & 37 & 015 \\
\hline & 20.70 & 5.63 & 36.83 & 6.35 & s & 75 & 0.026 & 1.000 & 0.031 & 620 & 033 \\
\hline & 21.56 & 5.63 & 35.60 & 6.35 & 13. & 624 & .028 & 0.953 & .033 & .643 & 35 \\
\hline & 22.92 & 5.63 & 35.10 & 6.35 & 12. & 04 & 16 & 66 & 0.019 & 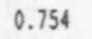 & \\
\hline & 23.03 & 5.63 & 5.35 & 6.35 & & & 0.010 & 10 & 0.012 & 39 & 013 \\
\hline & 22.07 & 5.63 & 36.69 & 6.35 & 14 & 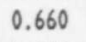 & 0.017 & 0.868 & 0.020 & 0.716 & 021 \\
\hline & 21.77 & 5.63 & 36.92 & 6.35 & 14. & 66 & 0.021 & 0.929 & 0.025 & 84 & 026 \\
\hline & 22.1 & 5.63 & 36.85 & 6.35 & 14. & 0.659 & 0.020 & 0.910 & .024 & 999 & 026 \\
\hline & 22.80 & 5.63 & 36.52 & 6.35 & 13. & 46 & 0.015 & 0.824 & .018 & .750 & 019 \\
\hline & 22.61 & 5.63 & 36.95 & 6.35 & 14 & 658 & 0.017 & 0.867 & 0.020 & 732 & .022 \\
\hline & 22.67 & 5.63 & 37.30 & 6.35 & 14. & 669 & 0.016 & 0.860 & 0.018 & 44 & .020 \\
\hline & 22.44 & 5.63 & 37.45 & 6.35 & 14. & 671 & 0.020 & 0.920 & 0.024 & 0.712 & .025 \\
\hline & 22.56 & 5.63 & 37.79 & 6.35 & 14.95 & 680 & 0.019 & 0.920 & 0.023 & 0.721 & .024 \\
\hline & 23.07 & 5.63 & 37.50 & 6.35 & 14.54 & 69 & 0.015 & 0.851 & 0.018 & 60 & 019 \\
\hline & 23.25 & 5.63 & 38.00 & 6.35 & 14 & 83 & 0.013 & 0.840 & 15 & 78 & 016 \\
\hline & 22.96 & 5.63 & 34 & 6. & & 5 & 0. & 0.879 & 0.017 & 59 & .018 \\
\hline & 22.66 & 5.63 & 38.75 & 6.35 & 15. & 703 & 0.021 & 0.972 & 0.025 & ( & .027 \\
\hline & 22.67 & 5.63 & 38.62 & 6.33 & 15. & 699 & 0.021 & 0.968 & 0.025 & 0.715 & .027 \\
\hline & 23.36 & 5.62 & 38.32 & 6.30 & 14.8 & .684 & 0.018 & 0.903 & 0.021 & 0.756 & .023 \\
\hline & 23.83 & 5.61 & 38.50 & 6.28 & 15. & 693 & 0.010 & 0.800 & 0.011 & 0.820 & .012 \\
\hline & 23.23 & 5.60 & 39.06 & 6.26 & 15. & 0.708 & 0.017 & 0.922 & 0.020 & 0.757 & .021 \\
\hline & 22.46 & 5.60 & 39.71 & 6.24 & 16. & 0.730 & 0.024 & 1.000 & 0.028 & 0.693 & .030 \\
\hline & 23.96 & 5.59 & 38.93 & 6.22 & 15.23 & 0.697 & 0.013 & 0.858 & 0.016 & 802 & .017 \\
\hline & 23.93 & 5.58 & 39.05 & 6.20 & 15.43 & 0.703 & 0.012 & 0.851 & 0.015 & 807 & 016 \\
\hline 64 & 23.44 & 5.57 & 39.92 & 6.19 & 16. & 129 & 0.017 & 0.950 & 0.020 & 764 & 021 \\
\hline 65 & 23.15 & 5.57 & 39.85 & 6.17 & & 28 & 0.020 & 0.987 & 0.023 & 170 & 025 \\
\hline & 3.58 & 5.56 & 39.85 & 6.15 & & 22 & 0.019 & 0.968 & 0.023 & 0.757 & .024 \\
\hline & .86 & 5.55 & 39.59 & 6. & & & 0.015 & 0.899 & 0.017 & 0.792 & 0.018 \\
\hline & .05 & .55 & 40.05 & 6.13 & 16 & 0.728 & 0.013 & 0.896 & 0.016 & 0.805 & 0.017 \\
\hline & 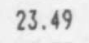 & 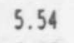 & 40.32 & 6.12 & 16. & 0.741 & 0.016 & 0.951 & 0.019 & 0.772 & 0.020 \\
\hline & 3.58 & 5.53 & 40.59 & 6.11 & 16.64 & 0.743 & 0.019 & 0.995 & 0.023 & 0.757 & .024 \\
\hline & .31 & 53 & 40.35 & 6.10 & 16.59 & 0.739 & 0.020 & 1.000 & 0.024 & 0.743 & 0.02 \\
\hline
\end{tabular}




\begin{tabular}{|c|c|c|c|c|c|c|c|c|c|c|c|}
\hline \multirow{4}{*}{ YEAR } & \multicolumn{5}{|c|}{ CHILDBEARING INDICES } & \multicolumn{6}{|c|}{$B O N G A A R$ IS INOICES } \\
\hline & AFB $(y=$ & & & & PRLS & & & & & & \\
\hline & & & & & & & & & & & \\
\hline & Mean & & $n$ & & & Cn & s. 8. & Cc & s.e. & $\mathrm{Ci}$ & e. \\
\hline & & & & & & 8 & 021 & & 025 & 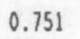 & 027 \\
\hline & & & & & & 732 & 0.014 & 0.908 & 0.016 & 0.797 & .017 \\
\hline & & & & & & .733 & 0.016 & 0.942 & 0.019 & 0.783 & 021 \\
\hline & & & & & & & 0.008 & 0.850 & 0.009 & 0.822 & 010 \\
\hline & & & & & & 726 & 0.011 & 0.857 & 0.013 & 0.829 & 013 \\
\hline & & & & & & 0 & & & 0.012 & 0.829 & 012 \\
\hline & & & & & & 0 & 0.011 & 0.873 & 0.013 & .813 & 014 \\
\hline & & & & & & & & 0.877 & 0.012 & & 013 \\
\hline & & & & & & 26 & 0.011 & 0.863 & 0.013 & 13 & 014 \\
\hline & & & & & & 9 & 0.011 & 0.834 & 0.013 & 29 & 014 \\
\hline & & & & & & 19 & 0.011 & 0.863 & 0.014 & 309 & 014 \\
\hline & & & & & & 12 & 0.011 & 0.845 & 0.013 & & 014 \\
\hline & & & & & & & 0.011 & 0.865 & & & 014 \\
\hline & & & & & & & 0.011 & 0.846 & 0.013 & & 014 \\
\hline & & & & & & & & & & & 014 \\
\hline & & & & & & & 0.013 & 0.855 & 0.015 & & 016 \\
\hline & & & & & & 34 & 0.011 & & 0.013 & & 014 \\
\hline & & & & & & 77 & 0.011 & 0.776 & 0.013 & 0.859 & .014 \\
\hline & & & & & & & 0.012 & 0.818 & .014 & & .015 \\
\hline & 24 & & & & & 90 & 0.011 & 0.797 & 0.013 & 0.852 & 014 \\
\hline & & & & & & 714 & 0.011 & 0.850 & 0.013 & .822 & .014 \\
\hline & & & & & & & 10 & 0.866 & 12 & 14 & 13 \\
\hline & & & & & & & 0.011 & 0.844 & .013 & .818 & 013 \\
\hline & & & & & & & 0.011 & 0.826 & 13 & 0.821 & 14 \\
\hline & & & & & & & 0.010 & 0.816 & .012 & .832 & \\
\hline & & & & & & & & 0.837 & 13 & 0.821 & 14 \\
\hline & & & & & & & & 0.819 & .013 & 0.824 & 014 \\
\hline & & & & & & & & & & 0.825 & \\
\hline & 2 & & & & & & & 12 & 13 & 0.831 & 014 \\
\hline & 2 & & & & & & 0.011 & 0.822 & 13 & & \\
\hline & & & & & & & & 0.842 & 13 & 0.828 & 14 \\
\hline & & & & & & & 0.011 & 0.809 & 13 & 0.850 & \\
\hline & & & & & & 6 & & 43 & 14 & 31 & 15 \\
\hline & & & & & & & 11 & 0.843 & 0.013 & 0.835 & 014 \\
\hline & & & & & & & 0.011 & & & 0.842 & .014 \\
\hline & & & & & & & 0.011 & & 0.013 & 0.840 & .014 \\
\hline & & & & & & & 0.012 & 0.749 & 0.014 & & \\
\hline & & & & & & & & & 0.012 & 6 & 013 \\
\hline & & & & & & & & 0.828 & 0.014 & .834 & \\
\hline & & & & & & & & 0.800 & 0.014 & 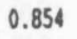 & 015 \\
\hline & & & & & & & 0.011 & & 0.013 & .842 & 14 \\
\hline & & & & & & & 0.012 & & & .855 & .015 \\
\hline & & & & & & 35 & 0.012 & 0.806 & 0.014 & & 015 \\
\hline & 25.0 & & & & & 90 & 0.012 & & & .851 & .01 \\
\hline & & & & & & & 0.012 & 0.815 & 0.014 & 0.848 & .015 \\
\hline & & & & & & 96 & 0.011 & 0.815 & 0.013 & & .014 \\
\hline & & & .25 & & & & & 0.820 & 0.014 & 0.845 & .015 \\
\hline & & & 8.88 & & & 0.684 & 0.011 & 0.793 & 0.013 & 0.853 & .014 \\
\hline & & & & & & .683 & 0.012 & 0.197 & 0.014 & & 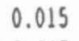 \\
\hline & 4.55 & 4.58 & 39.76 & 5.80 & 20.02 & .713 & 0.012 & 0.853 & 0.014 & 0.832 & 0.01 \\
\hline
\end{tabular}




\begin{tabular}{|c|c|c|c|c|c|c|c|c|c|c|c|}
\hline \multirow{4}{*}{ YEAR } & \multicolumn{5}{|c|}{ CHILDBEARING IMDICES } & \multirow{2}{*}{\multicolumn{6}{|c|}{$\begin{array}{l}\text { BONGAAR IS INDICES } \\
\text { ARRIAGE CONTRACEPTION INFECUNDABILITY }\end{array}$}} \\
\hline & \multicolumn{2}{|c|}{ AFB (years) } & \multicolumn{2}{|c|}{ ALB (years) } & \multirow[t]{2}{*}{ PRLS } & & & & & & \\
\hline & & & & & & \multicolumn{2}{|c|}{ (.)................ } & \multicolumn{2}{|c|}{ 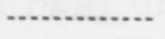 } & \multicolumn{2}{|c|}{...................... } \\
\hline & $\operatorname{ean}$ & s.e. & & & & 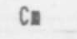 & & Cc & e. & $\mathrm{Ci}$ & s.e. \\
\hline 1822 & 4 & & & & & & & & & & \\
\hline 1823 & 4.64 & & 39.51 & & & & 0 & & & 834 & .015 \\
\hline 1824 & & & & & & & 0.012 & & & & .015 \\
\hline 1825 & .74 & - & & & & & 0.0 & & & & 014 \\
\hline 1826 & .89 & & & & & & 0.0 & & & & .015 \\
\hline 1827 & .04 & 7 & & & & & 0.1 & & & & 015 \\
\hline 1828 & & & & & & & 0.0 & & & & 015 \\
\hline 1829 & 4 & & & & & & 0.0 & & & & .015 \\
\hline 1830 & & & & & & & 2 & & & & 015 \\
\hline 1831 & & & & & & & & & & & 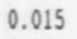 \\
\hline 1832 & & & & & & & 0. & & & 62 & 015 \\
\hline 183 & & & & & & & & & & & 015 \\
\hline 1834 & 09 & & & & & & 0.1 & & & 9 & 016 \\
\hline 1835 & & & & & & & 0. & & & & 016 \\
\hline 1836 & & & & & & & & & & & \\
\hline 1837 & 7 & & & & & & 0. & & & 82 & 016 \\
\hline 183 & & & & & & & & & & & 016 \\
\hline 1839 & & & & & & & 0. & & & & 015 \\
\hline 1840 & & & & & & & . & & & & 017 \\
\hline 1841 & & & & & & & 0.1 & & & & 016 \\
\hline 1842 & & & & & & & 0. & & & & 017 \\
\hline 2. & & & & & & & & & & & \\
\hline 1844 & & & & & & & 0. & & & & 016 \\
\hline 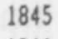 & & & & & & & & & & & \\
\hline 1846 & & & & & & & & & & & 015 \\
\hline 1847 & & & & & & & & & & & \\
\hline 1848 & & & & & & & 0. & & & & 017 \\
\hline 1849 & & 4 & & & & & 0 & & & 16 & 017 \\
\hline 1850 & & & & & & & 0.1 & & & & 016 \\
\hline 1851 & & 4.5 & & & & & 0. & & & & 018 \\
\hline 1 & & & & & & & & & & & \\
\hline 1853 & & & & & & & & & & & 017 \\
\hline 1854 & & & & & & & & & & & \\
\hline 1855 & & & & & & & & & & & 017 \\
\hline 856 & 1 & 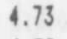 & & & & & 0 & & & 55 & 017 \\
\hline 85 & & & & & & & 0.1 & & & & 01 \\
\hline 858 & 2 & 3 & 39 & & & & 0.0 & & & 57 & 017 \\
\hline 9 & & & & & & & & & & & \\
\hline 60 & & & & & & & 0.1 & & & & 017 \\
\hline 861 & 7 & 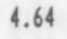 & & & & & & & & 43 & 016 \\
\hline 362 & & & & & & & 0.0 & & & & .017 \\
\hline 863 & & & & & & & & & & & .016 \\
\hline 864 & & & & & & & & & & & 017 \\
\hline 865 & & & & & & & & & & & .016 \\
\hline 1866 & & & & & & & & & & & \\
\hline 1867 & & & & & & & 0.1 & & & 0.871 & .017 \\
\hline 1868 & 26.81 & 5.28 & 37.72 & & & & & & & & .015 \\
\hline 1869 & & 4.59 & & & & & 0.015 & & 0.017 & & .019 \\
\hline 1870 & 25.35 & 4.60 & 39.20 & & & & 0.014 & & 0.016 & 0.853 & 0.018 \\
\hline 1871 & & & & & & & & & & & \\
\hline 1872 & 25.24 & 4.59 & 39.07 & 5.70 & 14.38 & 0.681 & 0.014 & 0.820 & 0.016 & 0.850 & 0.017 \\
\hline
\end{tabular}




\begin{tabular}{|c|c|c|c|c|c|c|c|c|c|c|c|}
\hline \multirow{4}{*}{ YEAR } & \multicolumn{5}{|c|}{ CHILDBEARING INDICES } & \multicolumn{6}{|c|}{$B O N G A A R I S$} \\
\hline & \multirow{2}{*}{\multicolumn{2}{|c|}{ AFB (years) }} & \multicolumn{2}{|c|}{ ALB (years) } & \multirow[t]{2}{*}{ PRLS } & \multirow{2}{*}{\multicolumn{2}{|c|}{ MARRIAGE }} & \multirow{2}{*}{\multicolumn{2}{|c|}{ CONTRACEPTION }} & \multicolumn{2}{|c|}{ INFECUNDABILITY } \\
\hline & & & & & & & & & & & \\
\hline & Mean & s.e. & Mean & & & CI & & Cc & & $\mathrm{Ci}$ & s.e. \\
\hline & & & & & & 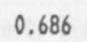 & 14 & & & & \\
\hline & & & & & & & & & & & \\
\hline & & & & & & & & & & & \\
\hline & & & & & & & & & & & \\
\hline & & & & & & & & & & & \\
\hline & & & & & & & 0.013 & & & & \\
\hline & & & & & & & & & & & \\
\hline & & & & & & & 0.013 & & & & \\
\hline & & & & & & & 0.013 & & & & \\
\hline & & & & & & & 0.013 & & & & \\
\hline & & & & & & & 0.0 & & & & \\
\hline & & & & & & & & & & & \\
\hline & & & & & & & 0.012 & & & & \\
\hline & & & & & & & 0.0 & & & & \\
\hline & & & & & & & 0.0 & & & & \\
\hline & & & & & & & & & & & \\
\hline & & & & & & & 0. & & & & \\
\hline & & & & & & & & & & & \\
\hline & & & & & & & 0.013 & & & & \\
\hline & & & & & & & 0.0 & & & & \\
\hline & & & & & & & 0. & & & & \\
\hline & & & & & & & 0.0 & & & & \\
\hline & & & & & & & & & & & \\
\hline & & & & & & & 0.0 & & & & \\
\hline & & & & & & & & & & & \\
\hline & & & & & & & 0.0 & & & & \\
\hline & & & & & & & & & & & \\
\hline & & & & & & & & & & & \\
\hline & & & & & & & 0 & & & & \\
\hline & & & & & & & 0 & & & & \\
\hline & & & & & & & & & & & \\
\hline & & & & & & & & & & & \\
\hline & & & & & & & & & & & \\
\hline & & & & & & & & & & & \\
\hline & & & & & & & & & & & \\
\hline & & & & & & & & & & & \\
\hline & & & & & & & & & & & \\
\hline & & & & & & & & & & & \\
\hline & & & & & & & & & & & \\
\hline & & & & & & & & & & & \\
\hline & & & & & & & & & & & \\
\hline & & & & & & & & & & & \\
\hline & & & & & & & & & & & \\
\hline & & & & & & & 0. & & & & \\
\hline & & & & & & & & & & & \\
\hline & & & & & & & 0.010 & & & & \\
\hline & & & & & & & & & & & \\
\hline & 26.06 & 5.1 & & & & & 0.011 & 0.698 & 13 & & \\
\hline & & & & & & & & & & & \\
\hline & & 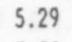 & 37.42 & 0.70 & & & & 0.636 & 0.012 & 0.928 & .013 \\
\hline & 5.97 & T.0 & 37.24 & 6.41 & 12.7 & .629 & 0.010 & 0.633 & 0.012 & 0.923 & .013 \\
\hline
\end{tabular}




\begin{tabular}{|c|c|c|c|c|c|c|c|c|c|c|c|}
\hline \multirow{4}{*}{ YEAR } & \multicolumn{5}{|c|}{ CHILDBEARING INDICES } & \multicolumn{4}{|c|}{$B O N G A A R T$} & \multicolumn{2}{|c|}{ I HDICES } \\
\hline & \multicolumn{2}{|c|}{8 (years) } & \multicolumn{2}{|c|}{ ALB (years) } & \multirow[t]{2}{*}{ PRLS } & \multicolumn{2}{|c|}{ MARRIAGE } & \multicolumn{2}{|c|}{ COHTRACEPTIOH } & \multicolumn{2}{|c|}{ INFECUKDABILITY } \\
\hline & & & & & & & & & & & \\
\hline & an & s.e. & in & & & Ca & & Cc & & al & \\
\hline & & & & & & & & & & & \\
\hline & & & & & & & & & & & \\
\hline & & & & & & & & & & & \\
\hline & & & & & & & & & & & \\
\hline & & & & & & & & & & & \\
\hline & & & & & & & & & & & \\
\hline & & & & & & & & & & & \\
\hline & & & & & & & & & & & \\
\hline & & & & & & & & & & & \\
\hline & & & & & & & & & & & \\
\hline & & & & & & & & & & & \\
\hline & & & & & & & & & & & \\
\hline & & & & & & & & & & & \\
\hline & & & & & & & & & & & \\
\hline & & & & & & & & & & & \\
\hline & & & & & & & & & & & \\
\hline & & & & & & & & & & & \\
\hline & & & & & & & & & & & \\
\hline & & & & & & & & & & & \\
\hline & & & & & & & & & & & \\
\hline & & & & & & & & & & & \\
\hline & & & & & & & & & & & \\
\hline & & & & & & & & & & & \\
\hline & & & & & & & & & & & \\
\hline & & & & & & & & & & & \\
\hline & & & & & & & & & & & \\
\hline & & & & & & & & & & & \\
\hline & & & & & & & & & & & \\
\hline & & & & & & & & & & & \\
\hline & & & & & & & & & & & \\
\hline & & & & & & & & & & & \\
\hline & & & & & & & & & & & \\
\hline & & & & & & & & & & & \\
\hline & & & & & & & & & & & \\
\hline & & & & & & & & & & & \\
\hline & & & & & & & & & & & \\
\hline & & & & & & & & & & & \\
\hline & & & & & & & & & & & \\
\hline & & & & & & & & & & & \\
\hline & & & & & & & & & & & \\
\hline & & & & & & & & & & & \\
\hline & & & & & & & & & & & \\
\hline & & & & & & & & & & & \\
\hline & & & & & & & & & & & \\
\hline & & & & & & & & & & & .027 \\
\hline & & & & & & & & & & & .032 \\
\hline & 3 & 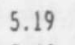 & & & & & & & & & \\
\hline & .44 & & & & & & & & & & \\
\hline & .50 & & & & & & & & & & \\
\hline & & & & & & & & & & & \\
\hline & & & & & & & 0.024 & 0.177 & .028 & 0.974 & 0.030 \\
\hline
\end{tabular}


CHILDBEARING INDICES

AFB (years) ALB (years) PRLS
BONGAARIS INDICES

MARRIAGE CONTRACEPTION INFECUNDABILITY

\begin{tabular}{|c|c|c|c|c|c|c|c|c|c|c|c|}
\hline & Mean & $s$ & ean & & 1 & $\mathrm{~cm}$ & s.e. & $\mathrm{CC}$ & & $\mathrm{Ci}$ & e \\
\hline & 4.62 & .62 & & & & 0.458 & & & & & \\
\hline & & 5.01 & & & & & & & & & \\
\hline & 24.94 & 5.02 & sen & & & 0.460 & & & & & \\
\hline & 25.16 & .02 & & & & & & & & & \\
\hline & & 5.04 & . & & & 0.4 & & & & & \\
\hline & & 5.03 & & & & 0. & & & & & \\
\hline & & & & & & & & & & & \\
\hline & & 4.97 & & & & 0. & & & & & \\
\hline & & & & & & & & & & & \\
\hline & & 01 & & & & & & & & & \\
\hline & & & & & & & & & & & \\
\hline & & & & & & & & & & & \\
\hline & 4 & 63 & & & & & & & & & \\
\hline & & & & & & & & & & & \\
\hline & & 59 & & & & 0 & & & & & \\
\hline & & & & & & 0 & & & & & \\
\hline & & & & & & 0. & & & & & \\
\hline & & & & & & & & & & & \\
\hline & & & & & & & & & & & \\
\hline & & & & & & & & & & & \\
\hline & & & & & & 0. & & & & & \\
\hline & or & 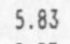 & & & & & & & & & \\
\hline & & & & & & 0. & & & & & \\
\hline & & 9) & & & & & & & & & \\
\hline & & & & & & 0. & & & & & \\
\hline & & & & & & 0. & & & & & \\
\hline & 25 & & & & & & & & & & \\
\hline & & .07 & & & & & 0. & & & & \\
\hline & 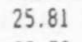 & 11 & & & & & & & & & \\
\hline & & & & & & & & & & & 02 \\
\hline & & 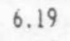 & & & & & & & & & \\
\hline & & & & & & & & & & & .02 \\
\hline & & & & & & 0. & 0. & & & & \\
\hline & 2563 & 2 & & & & & & & & & .02 \\
\hline & & & & & & & 0.1 & 0. & & & \\
\hline & & 6.3 & & & & & & & & & .02 \\
\hline & & & & & & & & 0. & & & \\
\hline & & 6. & & & & & & & & & .02 \\
\hline & & & & & & & & & & & \\
\hline & & 6. & & & & 0. & & & & & \\
\hline & & 6.5 & & & & & & & & & .0 \\
\hline & & & & & & & & & & & 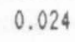 \\
\hline & & 6.8 & & & & & & & & & 0 \\
\hline & & & & & & & & 0.240 & & & \\
\hline & & 6.7 & & & & & & & & & .0 \\
\hline & & 6.7 & & & & & 0.019 & 0.233 & 0.023 & & 0 \\
\hline & & 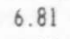 & 28.82 & 9. & 6. & & & & & & \\
\hline & 25.42 & . & 28.77 & 9.43 & & 0.412 & 0.020 & 0.225 & 0.023 & 0.956 & 0 \\
\hline
\end{tabular}




\section{References}

Andorka, R. (1978). Determinants of Fertility in Advanced Societies. London.

Bongaarts, J.B. (1978). A framework for analyzing the proximate determinants of fertility. Population and Development Review 4(1): 105-132.

Bongaarts, J.B. and Potter, R.G. (1983). Fertility, Biology, and Behavior: An Analysis of the Proximate Determinants. New York: Academic Press.

Box, G.E.P. and Jenkins, G.M. (1976). Time Series Analysis Forecasting Control. Revised Edition. San Francisco: Holden-Day.

Breckenridge, M.B. (1983). Age, Time, and Fertility. New York: Academic Press.

Calot, G. and Blayo, C. (1982). Recent course of fertility in Western Europe. Population Studies 36(3): 349-372.

Carlsson, G. (1970). Nineteenth century fertility oscillations. Population Studies 24(3): 413-422.

Carter, L.R. and Lee, R.D. (1986). Joint forecasts of U.S. marital fertility, nuptiality, births, and marriages using time series models. Journal of the American Statistical Association 81: 902-911.

Coale, A.J. (1974). The demographic transition. In: United Nations. The Population Debate, Dimensions and Perspectives. Papers of the World Population Conference, Bucharest. New York: United Nations Publications, 347-356.

Cox, D.R. (1962). Renewal Theory. London: Methuen and Company Ltd.

El-Khorazaty, M.N. (1989). A century of demographic and socioeconomic dynamics in Egypt. Population Bulletin of United Nations - Economic and Social Commission for Western Asia 34 (June): 3-44.

El-Khorazaty, M.N. (1991). Estimation of fertility-inhibiting indices using vital registration data. Genus 47: forthcoming.

El-Khorazaty, M.N. and Horne, A.D. (1992). Dynamics of childbearing statistics in twentieth century developing and developed countries. Journal of Comparative Family Studies 23(1): 13-37.

Ewbank, D.C. (1989). Estimating birth stopping and spacing behavior. Demography 26(3): 473-483.

Festy, P. (1984). Fertility in Western Countries (1870-1970). Population Studies Translation Series No. 7. Bangkok: United Nations Economic and Social Commission for Asia and the Pacific.

Finland, Central Statistical Office. (1975). The Population of Finland: A World Population Monograph. Helsinki: Central Statistical Office.

Hajnal, J. (1965). European marriage patterns in perspective. In: Glass, D.V. and Eversley, D. (eds.), Population in History. London: Edward Arnold, 101-143.

Hajnal, J. (1983). Two kinds of pre-industrial household formation systems. In: Wall, R., Robin, J., and Laslett, P. (eds.), Family Forms in Historic Europe. Cambridge, MA: Cambridge University Press, 65-104.

Henry, L. (1961). Some data on natural fertility. Eugenics Quarterly 18(2): 81-91.

Hill, A.G. (1985). A practical guide to estimating the Bongaarts indices of the proximate determinants of fertility. In: Shorter, F.C. and Zurayk, H. (eds.). Population Factors in Development Planning in the Middle East. New York and Cairo: The Population Council.

Horne, A.D. and El-Khorazaty, M.N. (1987). Childbearing indices in the Arab World. Population Bulletin of UN-ESCWA 31: 77-111.

Horne, A.D., El-Khorazaty, M.N., and Suchindran, C.M. (1990). Statistical modeling of selected aspects of the childbearing process with application to World Fertility Survey countries. Mathematical Population Studies 2(3): 183-207.

Kaukiainen, Y. (1973). Considerations of the effects and interaction of nativity (natality) and mortality on preindustrial population growth in Finland. Historiallinen Aikakauskirja (Helsinki) 2: 103-121.

Knodel, J. (1987). Starting, stopping, and spacing during the early stages of fertility transition: the experience of German village populations in the 18th and 19th centuries. Demography 24(2): 143-162.

Land, K.C. and Cantor, D. (1983). ARIMA models of seasonal variation in U.S. birth and death rates. Demography 20(4): $541-568$.

Lutz, W. (1987a). Factors associated with the Finnish fertility decline since 1776. Population Studies 41(3): $463-482$.

Lutz, W. (1987b). Finnish Fertility Since 1722. Helsinki: The Population Research Institute.

Lutz, W. and Pitkänen, K.J. (1986). Tracing Back the Eighteenth Century »Nuptiality Transition» in Finland. Collaborative paper CP-86-1. Laxenburg, Austria: International Institute for Applied Systems Analysis.

McCleary, R. and Hay, R.A., Jr. (1980). Applied Time Series Analysis for the Social Sciences. Beverly Hills: Sage Publications.

Mielke, J.H. and Pitkänen, K.J. (1989). War demography: the impact of the 1808-1809 War on the civilian population of a land: Finland. European Journal of Population 5: 373-398.

Mielke, J.H., Pitkänen, K.J., Jorde, L.B., Fellman, J.O., and Eriksson, A.W. (1987). Demographic patterns in the Aland Islands, Finland, 1750-1900. Yearbook of Population Research in Finland XXV, 
$57-74$.

Mitchell, B.R. (1981). European Historical Statistics 1750-1975. Second revised edition. New York: Facts on File.

Nordic Council of Ministers (several years). Yearbook of Nordic Statistics. Copenhagen: The Nordic Council of Ministers and the Nordic Statistical Secretariat.

Pitkänen, K.J. (1984). The history of population and demographic data collection in Finland. In: Finnish Demographic Society. National Population Bibliography of Finland 1945-1978. Belgium: International Union for the Scientific Study of Population.

Population Research Institute. (several years). Yearbook of Population Research in Finland. Helsinki: The Population Research Institute.

Turpeinen, O. (1978). Regional differences in fertility rate and family planning in pre-industrial Finland. In: Akerman, S., Johansen, H.C., and Gaunt, D. (eds.), Chance and Change: Social and Economic Studies in Historical Demography in the Baltic Area. Odense: Odense University Press.

Turpeinen, O. (1979). Fertility and mortality in Finland since 1750. Population Studies 33(1): $101-114$. Turpeinen, O. (1986). Personal communications.

United Nations. (1989). World Population Prospects 1988. New York: United Nations Publications.

United Nations. (several years). Demographic Yearbook. New York: United Nations Publications.

Watkins, S.C. (1990). From local to national communities: The transformation of demographic regimes in western Europe, 1870-1960. Population and Development Review 16(2): 241-272.

\begin{abstract}
A new time series data set of childbearing and fertility-inhibiting indices for Finland since 1722 is constructed. Calculation of these macro-level indices is accomplished by the application of new demographic and statistical methodologies, which require only knowledge of age-specific fertility rates, available for Finland since 1776, and the Box-Jenkins time series forecasting technique. The results depict that Finland passed through various childbearing patterns. These patterns are characterized by increasing ages at first and last birth in the eighteenth century to stabilization in the following century at high levels. Since the beginning of the twentieth century, ages at last birth declined dramatically while ages at first birth first increased, then declined in the 1940s and stayed at that low level later on. Increases in both indices have been witnessed since the mid-1970s.
\end{abstract}

